GA-A20972

\title{
THERMAL ANALYSIS AND DESIGN OF POLARIZER MIRRORS FOR WAVEGUIDES IN THE DIII-D TOKAMAK
}

by

C.B. BAXI, J.L. DOANE, and D.L. SEVIER

JULY 1992

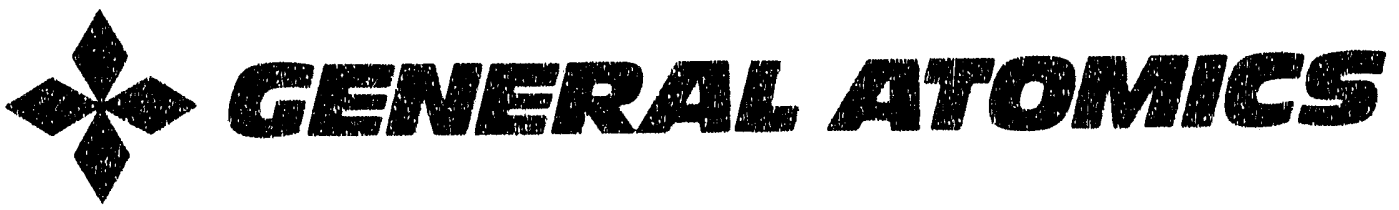




\section{DISCLAIMER}

This report prepared an account of work sponsored by an afency of the United Statea Government. Neither the United States Government nor any agency thereof, nor any of their employees, makes any wartanty, express or implied, or assumes any legal liability or responsibility for the accuracy, completeness, or usefulness of any information, apparatus, product, or process disclosed, or represents that its use would not infringe privately owned rights. Reference herein to any specific commercial product, process, or service by trade name, tredemark, manufacturer, or otherwise, does not necessarily constitute or imply ito endorsement, recommendation, or favoring by the United States Government or any agency thereof. The views and opinions of authon expressed herein do not neressarily state or reflect thase of the United States Government or any agency thereof. 


\title{
THERMAL ANALYSIS AND DESIGN OF POLARIZER MIRRORS FOR WAVEGUIDES IN THE DIII-D TOKAMAK
}

\author{
by \\ C.B. BAXI, J.L. DOANE, and D.L. SEVIER
}

This is a preprint of a paper to be presented at the International Society for Optical Engineering, July 19-24, 1992, San Diego, California, and to be printed in the Proceedings.

\author{
Work supported by \\ U.S. Department of Energy \\ Contract No. DE-AC03-89ER51114
}

GENERAL ATOMICS PROJECT 3466

JULY 1992

\section{GENERAL ATOMICS




\title{
Thermal analysis and design of polarizer mirrors for waveguides in the DIII-D tokamak
}

\author{
C.B. BAXI, J.L. DOANE, and D.L. SEVIER \\ General Atomics \\ P.O. Box 85608, San Diego, California 92138-5608
}

\begin{abstract}
A new high power electron cyclotron heating (ECH) system designed to operate at $110 \mathrm{GHz}$ with a power output of $2 \mathrm{MW}$ has been introduced on DIII-D. All components of the system are capable of handling a 10 second pulse at an interval of 10 minutes. Transmission of ECH power from the the source (a millimeter-wave gyrotron) to the plasma through waveguide miter bends may change the polarization and rotate the polarization major axis. Polarizing elements are therefore required to correct for the effect of transmission lines and also to generate proper polarization for coupling into the plasma. Rotating mirrors with different rectangular grooved gratings in two successive miter bends can generate the required wide range of elliptical polarizations. Peak heat fluxes due to ohmic losses in these mirrors are several $\mathrm{MW} / \mathrm{m}^{2}$ for a $0.5 \mathrm{MW}$ gyrotron power. The complex distribution of losses in the grooves requires a detailed thermal stress analysis to ensure that temperature and stress limits are not exceeded. The desired pulse length is $10 \mathrm{sec}$, with a cooling time of $10 \mathrm{~min}$ between pulses. The temperature rise in the polarizing mirrors must be limited to less than $300^{\circ} \mathrm{C}$ to prevent thermal fatigue and outgassing in the vacuum lines. This paper presents an analysis for the polarizing mirrors for the DIII-D ECH system.
\end{abstract}

\section{INTRODUCTION}

The DIII-D tokarnak (Fig. 1) is an experimental fusion device located at General Atounics that has been operating since February 1986. ${ }^{1}$ Electron cyclotron heating (ECH) is one of the methods used at DIII-D to heat the plasma. A new high-power electron cyclotron (EC) system has been introduced on DIII-D. ${ }^{2}$ This system is designed to operate at $110 \mathrm{GHz}$ with a total output power of $2 \mathrm{MW}$.

The $110 \mathrm{GHz}$ ECH system consists of eight major components as shown in Fig. 2. These components are:

1. High Voltage ( $80 \mathrm{kV}$ at $80 \mathrm{~A}$ ) Power Supply.

2. Four Varian VGT-8011 Gyrotrons with output power of $500 \mathrm{~kW}$ each.

3. Superconducting Magnets.

4. Gyrotron Tank.

5. Control System.

6. Mode Convertor.

7. Transmission System.

8. Launcher. 


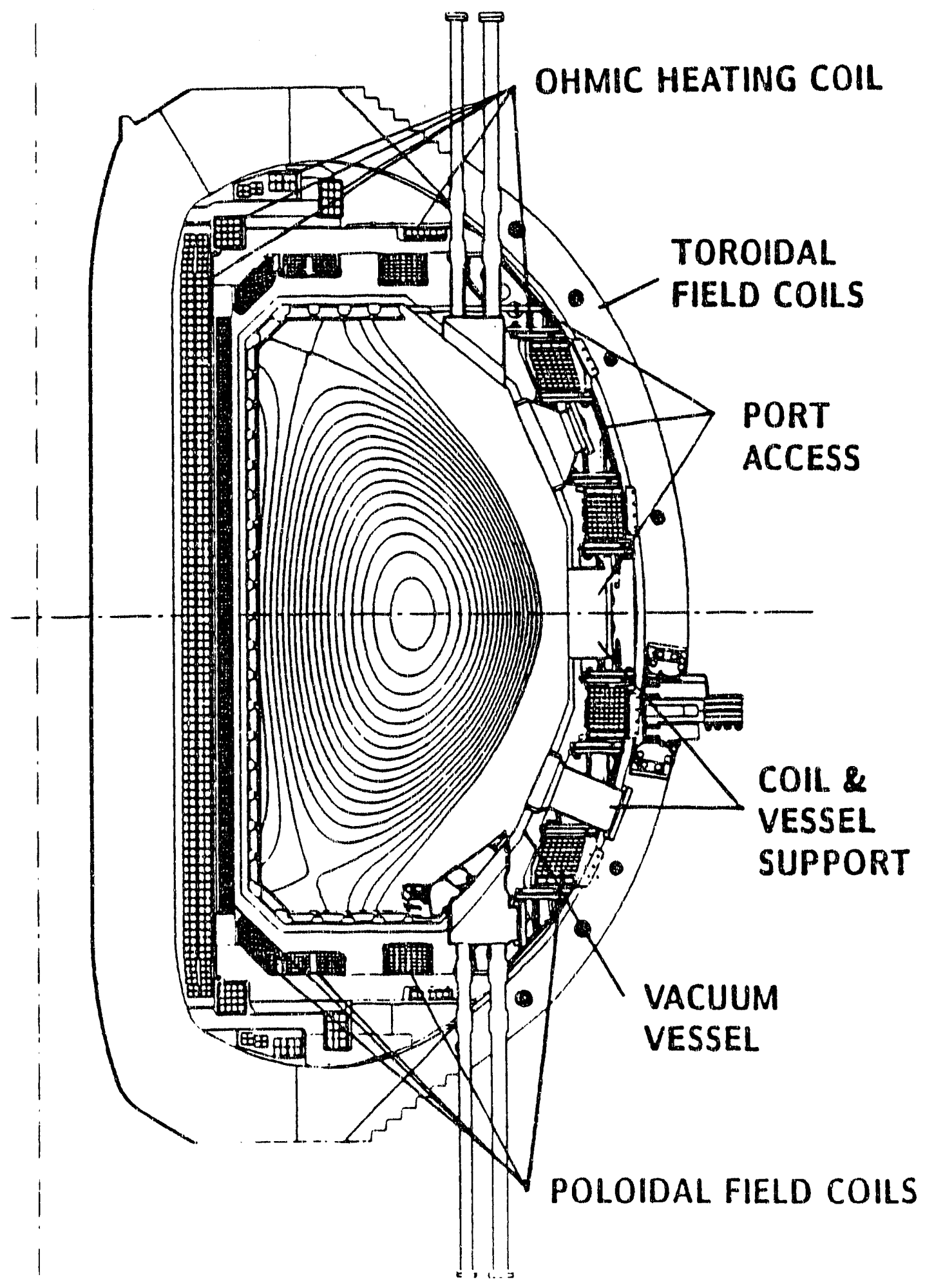

Fig. 1. Cross-section of DIII-D tokamak. 


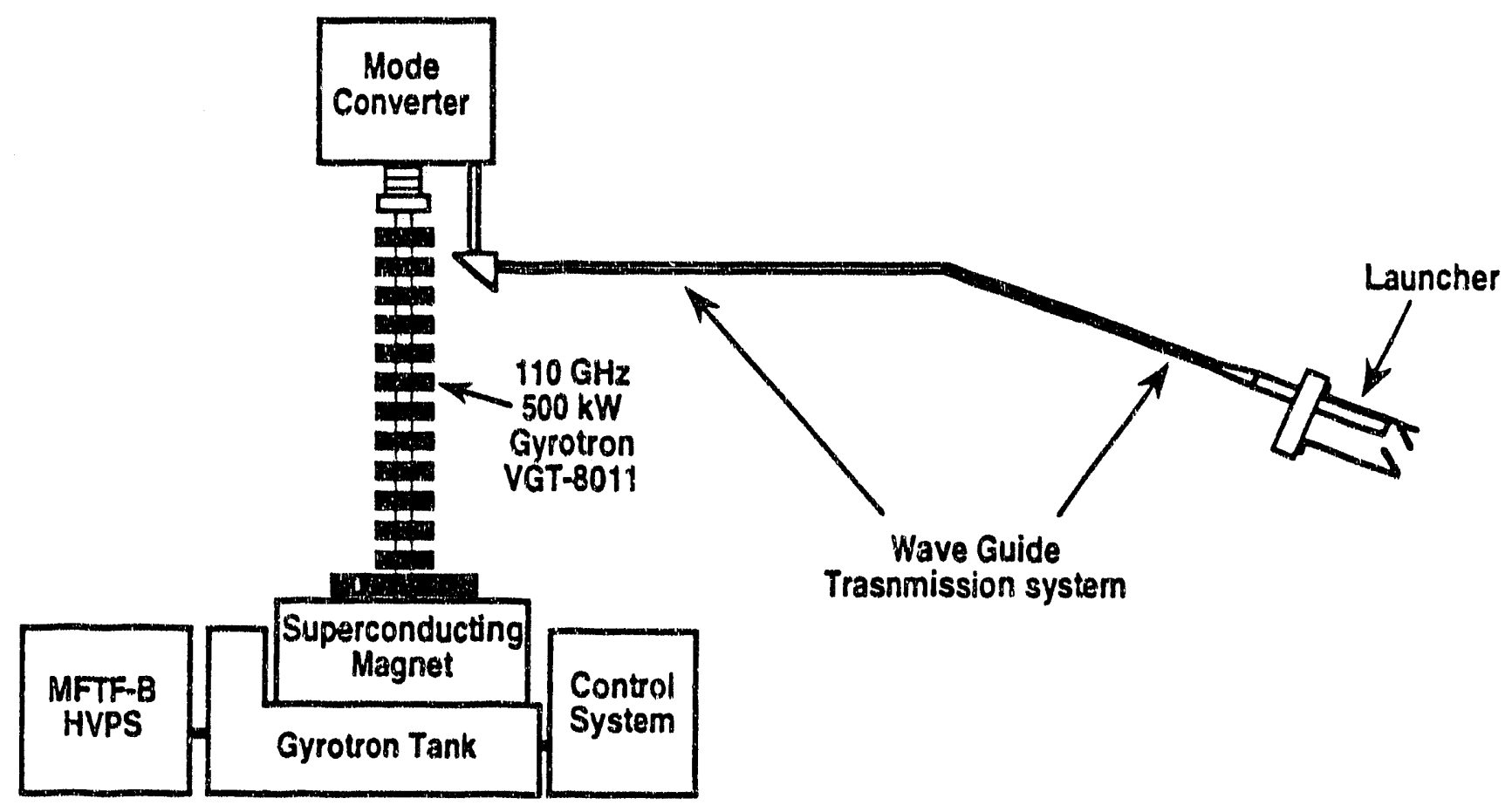

Fig. 2. The $110 \mathrm{GHz}$ ECH system.

Components of the transmission system are shown in Fig. 3. Transmission of the ECH power from the gyrotron to the plasma through mirrors used to negotiate the bends changes the polarization and rotates the polarization major axis of the $\mathrm{HE}_{11}$ mode. In order to generate proper polarization for coupling with plasma, mirrors with rectangular gratings in the miter bends are used. ${ }^{3}$ Two gratings with different groove depths in successive miter bends are sufficient to generate a wide range of polarizations. The polarization control is obtained by rotating the mirrors. This paper presents the thermal design and analysis of these mirrors.

\section{DESCRIPTION OF THE MIRROR}

The polarizer mirrors are made of OFHC copper and are water-cooled by a copper tube brazed to the fixed part of the mirror (Figs. 4 and 5). The mirror can be rotated through $360 \mathrm{deg}$ to obtain the desired polarization. The mirrors are $4.1 \mathrm{~cm}$ thick and $4.49 \mathrm{~cm}$ in diameter at the waveguide interior. The surface of the mirror is grooved as shown. The pitch of the grooves is $0.96 \mathrm{~mm}$ and the groove width is $0.74 \mathrm{~mm}$. The depth of the grooves is either 0.53 or $0.89 \mathrm{~mm}$. The polarizer mirror assembly consists of three parts as shown in Fig. 5 . Copper tubes, $1 \mathrm{~cm}$ ir diameter are brazed to fixed part of the mirror. Water flow at a rate of $60 \mathrm{~cm}^{3} / \mathrm{s}(1 \mathrm{gpm})$ provides sufficient cooling for the base design of $500 \mathrm{~kW}$ mirror. The mirror can be rotated through $360^{\circ}$ to obtain proper polarization. 


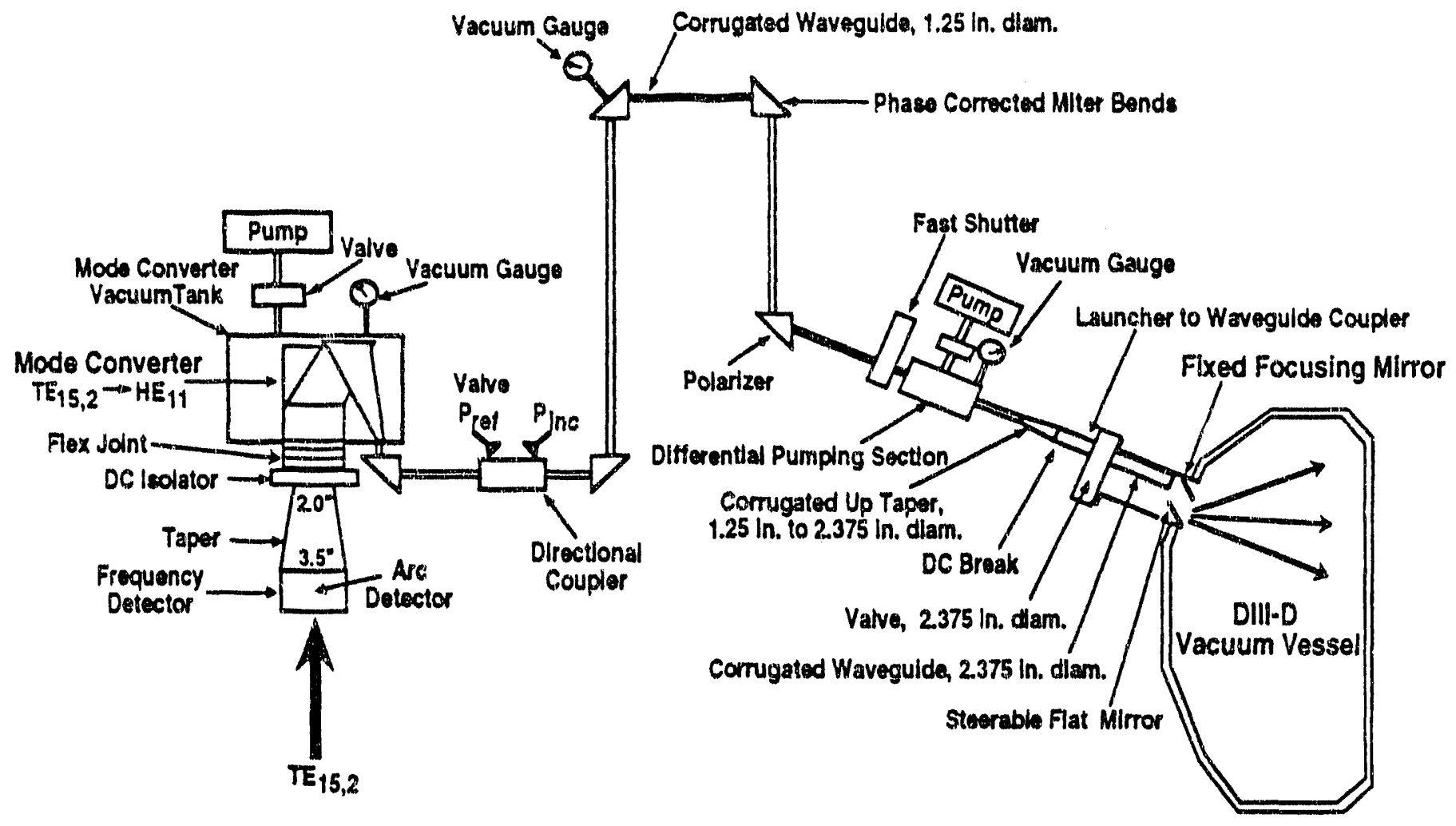

Fig. 3. Transmission and mode conversion.

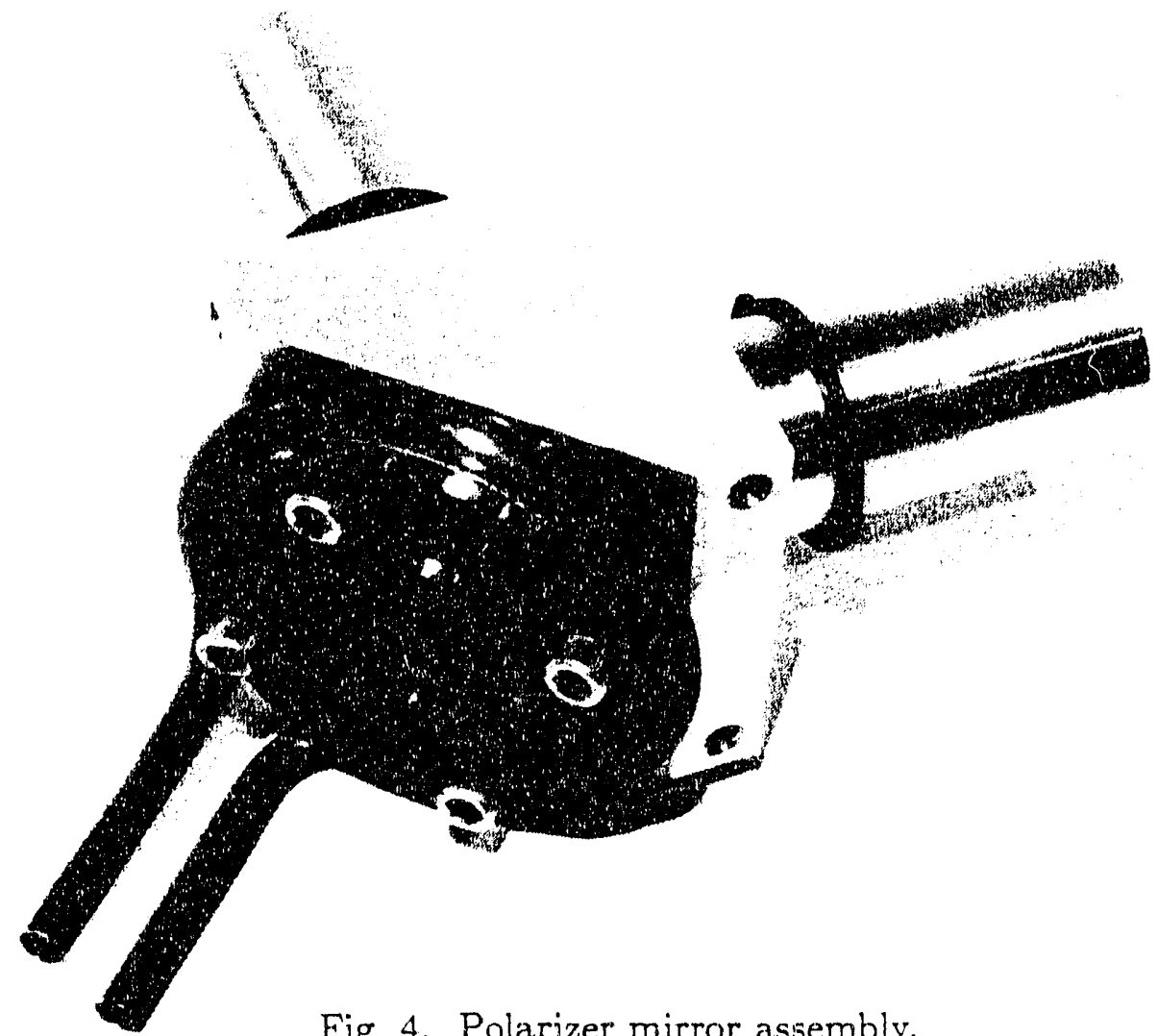

Fig. 4. Polarizer mirror assembly. 


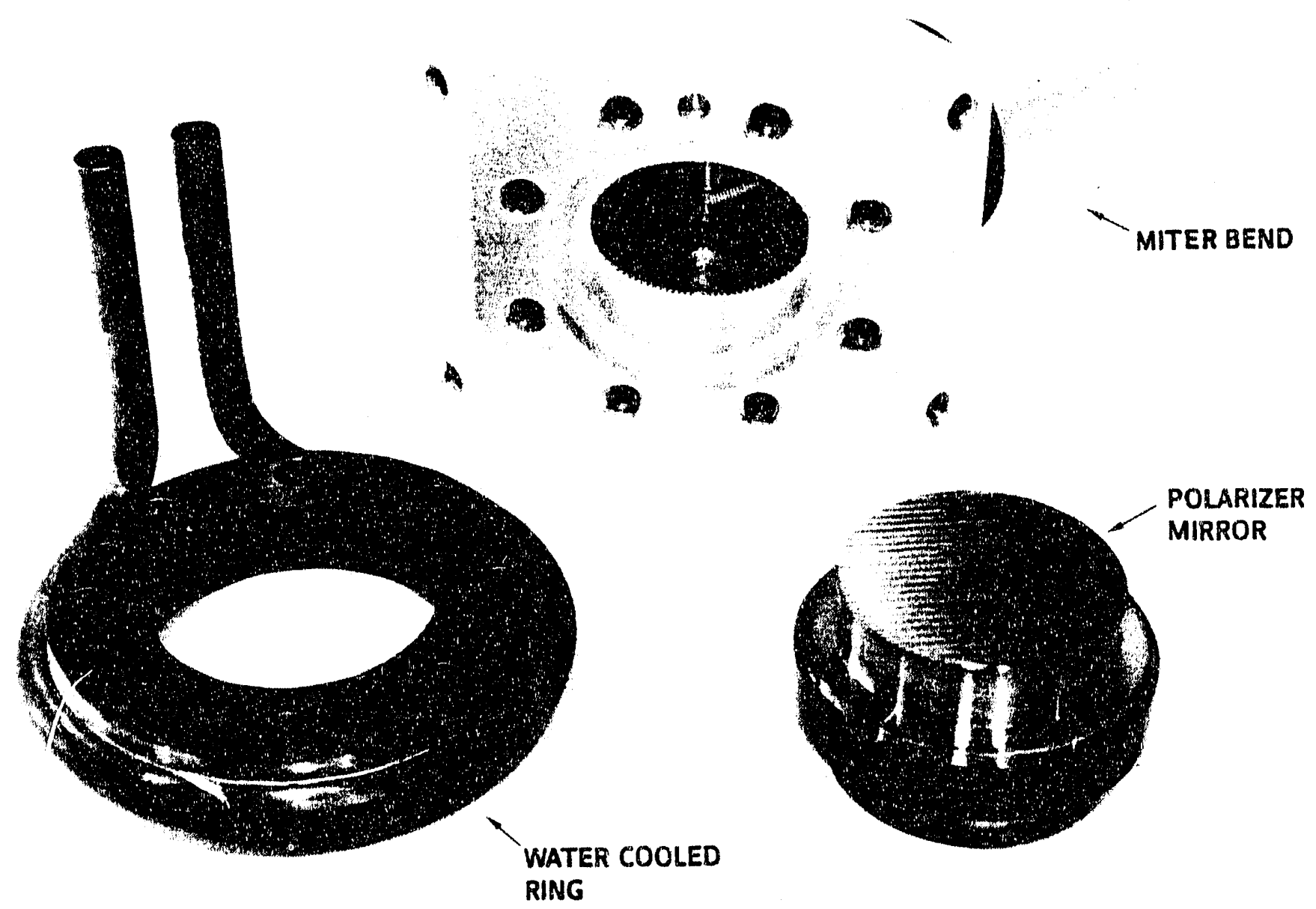

Fig. 5. Components of the mirror assembly.

\section{LOSS DISTRIBU'TION}

The radial loss distribution on the surface of the mirror is given by ${ }^{3}$ the function

$$
q^{\prime \prime}=J_{0}^{2}(2.405 r / R),
$$

where

$$
\begin{aligned}
q^{\prime \prime} & =\text { heat loss, } \mathrm{W} / \mathrm{cm}^{2}, \\
r & =\text { distance from the center }, \\
R & =\text { radius of the mirror }=2.245 \mathrm{~cm} .
\end{aligned}
$$

The above function is shown in Fig. 6 and has a peak to average ratio of 4.0. 


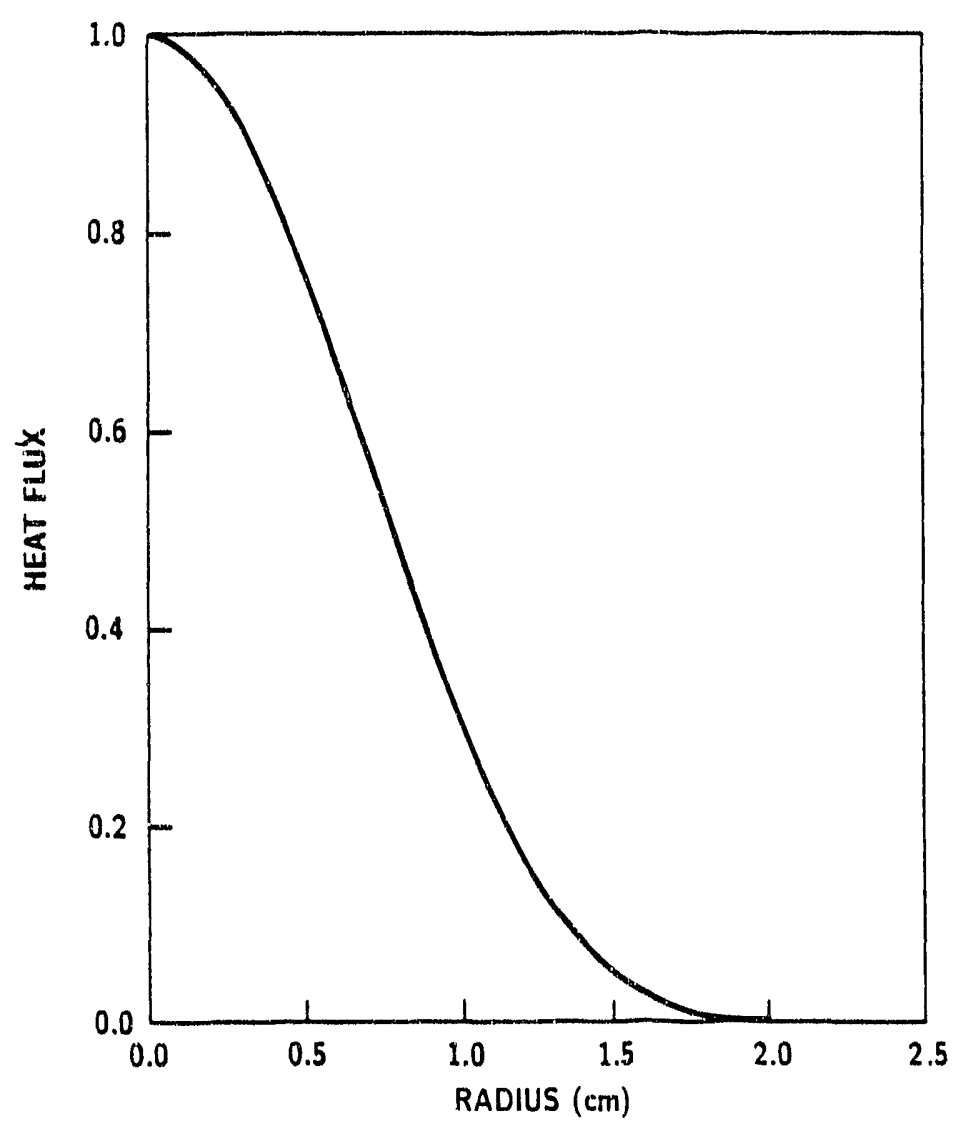

Fig. 6. Normalized radial loss distribution on mirrors.

In addition to the radial distribution, the losses have the following approximate distribution inside the grooves:

\begin{tabular}{lcccc} 
& $\begin{array}{c}\text { Groove Depth } \\
\text { (mm) }\end{array}$ & $\begin{array}{c}\text { Ridges } \\
\text { (top) }\end{array}$ & $\begin{array}{c}\text { Ridges } \\
\text { (side)* }\end{array}$ & $\begin{array}{c}\text { Bottom } \\
\text { of Groove* }\end{array}$ \\
\hline Polarizer 1 & 0.89 & 25 & 50 & 25 \\
Polarizer 2 & 0.53 & 16 & 50 & 33 \\
\hline
\end{tabular}

*\% of total heat flux.

The losses are proportional to the square root of the local electrical resistivity of the mirror material, and also can vary by a factor of two depending on the incident polarization. ${ }^{4}$ The maximum total heat loss in the mirror at $20^{\circ} \mathrm{C}$ is calculated to be $750 \mathrm{~W}$ for a $500 \mathrm{~kW}$ gyrotron and $1500 \mathrm{~W}$ for a $1 \mathrm{MW}$ gyrotron output. Thus, the heat loss distribution is a function of gyrotron output, local temperature during the transient, radial distance from the center, and location (i.e., ridge, side, or top ) in the groove. 


\section{ANALYSIS OF GROOVES}

To model distribution of losses in the grooves as well as radial distribution, a very complex 3-D analysis would possibly be required. Hence, first a simple analysis to investigate the effect of the loss distribution inside the grooves was performed. A 2-D finite element model of a single groove was prepared and analyzed on the code TOPAZ2D. ${ }^{5}$ Analysis was performed for a $10 \mathrm{sec}$ pulse taking into account the distribution of heat losses as described above. An analysis was also performed of a flat surface subjected to same heat flux. The difference in the peak temperature rise was about $8 \%$. Hence, it was concluded that the 2-D model which correctly modeled the radial (and temperature) dependence of losses will be adequate to analyze the thermal problem. The temperature calculated by such a 2-D model will be well within the uncertainty of input data. This analysis also indicated that there was no significant disference in the two polarizers discussed above. This analysis verified that the stresses caused by temperature differences at the end of the pulse were acceptable.

\section{MIRROR ANALYSIS}

A 2-D axisymmetric finite element of the mirror without the ridges was now prepared. The radial distribution and temperature dependence of the losses was taken into consideration in this model. Figures 7 and 8 show the temperature distribution in the mirror at the end of a $10 \mathrm{sec}$ pulse after many cycles for $500 \mathrm{~kW}$ and $1 \mathrm{MW}$ gyrotron output. The mirror reaches a quasi-steady-state after about ten cycles of $10 \mathrm{sec}$ pulses followed by $600 \mathrm{sec}$ cooldown between pulses. Thus, the mirror will reach a peak temperature of $173^{\circ} \mathrm{C}$ for a $500 \mathrm{~kW}$ gyrotron and a peak temperature of $360^{\circ} \mathrm{C}$ for a $1 \mathrm{MW}$ gyrotron.

The mirror temperature is above the desired temperature of $300^{\circ} \mathrm{C}$ for the $1 \mathrm{MW}$ gyrotron power. A large part of this increase (about $150^{\circ} \mathrm{C}$ ) is due to ratchetting, i.e., the mirror does not cool down to water temperature in between pulses. This could be remedied by increasing the cooling effectiveness. The cooling effectiveness can be increased by, increasing the water flow rate, increasing the brazed length of the tube, increasing the contact area between movable and fixed (cooled) parts of the mirror and increasing the contact pressure between two parts of the mirror assembly. Since $1 \mathrm{MW}$ gyrotron operation is not planned in the near future, the design modification has been postponed. The mirror has adequate safety margin for $500 \mathrm{~kW}$ operation.

\section{CONCLUSIONS}

1. The polarizer mirror design presented here has adequate margin for $500 \mathrm{~kW}$ gyrotron output.

2. The mirror could be operated at $1 \mathrm{MW}$ gyrotron output by improving the cooling system. This could be achieved by increasing the contact area between fixed and movable parts of the mirror and increasing the length of the water cooled tube brazed to the fixed part of the mirror.

\section{ACKNOWLEDGEMENT}

This is a report of work sponsored by the U.S. Department of Energy under Contract No. DE-AC03-89ER51114. 


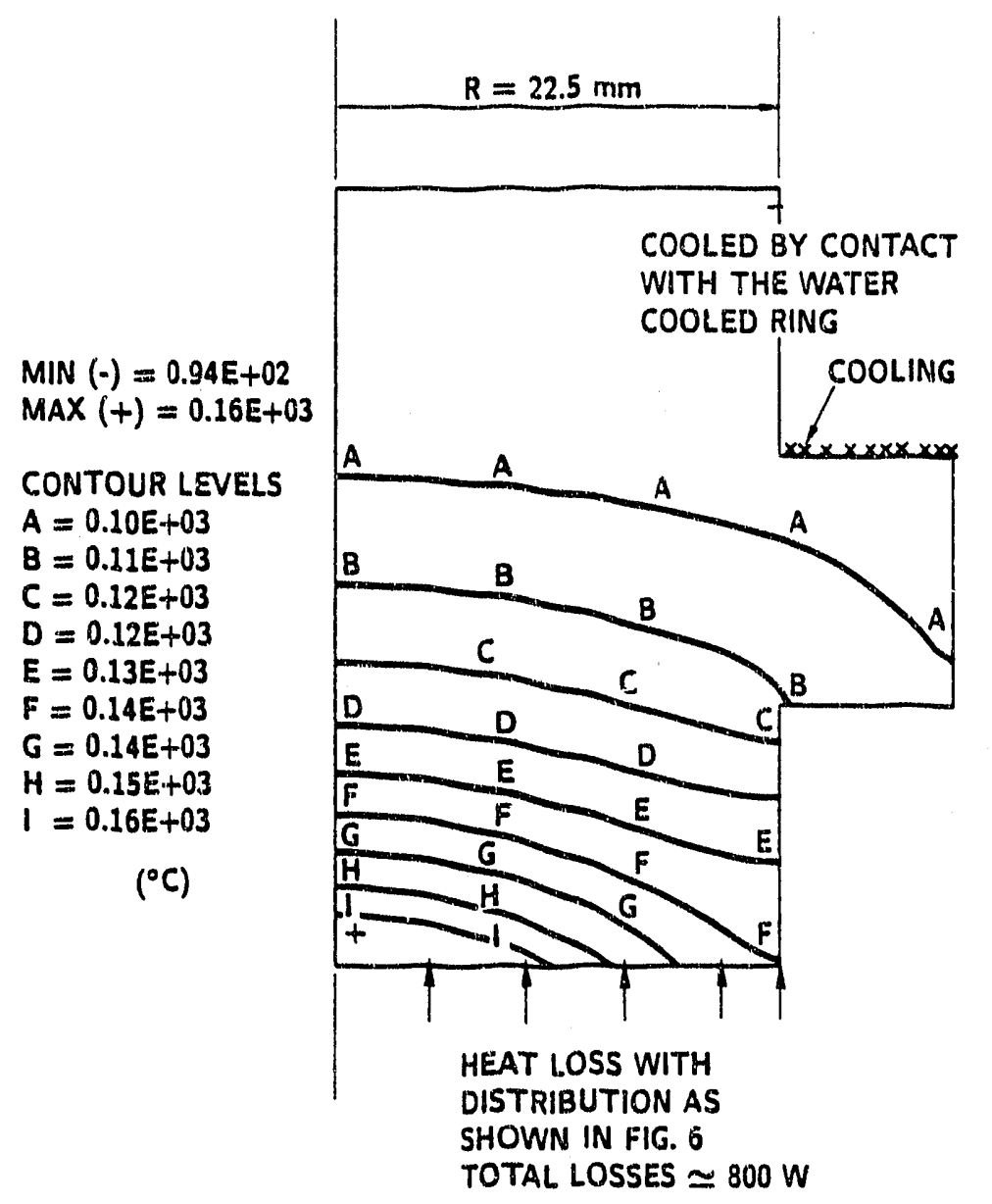

Fig. 7. Temperature distirbution in the polarizer mirror at the end of $10 \mathrm{sec}$ pulses for $0.5 \mathrm{MW}$ of transmitted power.

\section{REFERENCES}

1. Program Staff, "Systern Design Description of DIII-D," General Atomics Report GA-A19264 (1989).

2. W.P. Cary et al., "110 GHz ECH on DIII-D: System Overview and Initial Operation," Symposium on Fusion Engineering, San Diego, October 1991.

3. J. Doane, "Grating Polarizers in Vaveguide Miter Bends," submitted to International Journal of Infrared and Millimeter Waves.

4. J.A. Stratton, "Electromagnetic Theory," McGraw-Hill, New York (1991), Section 9.9.

5. A.B. Shapiro, "TOPAZ - A finite Element Heat Conduction Code," UCID-20045, March 1984. 


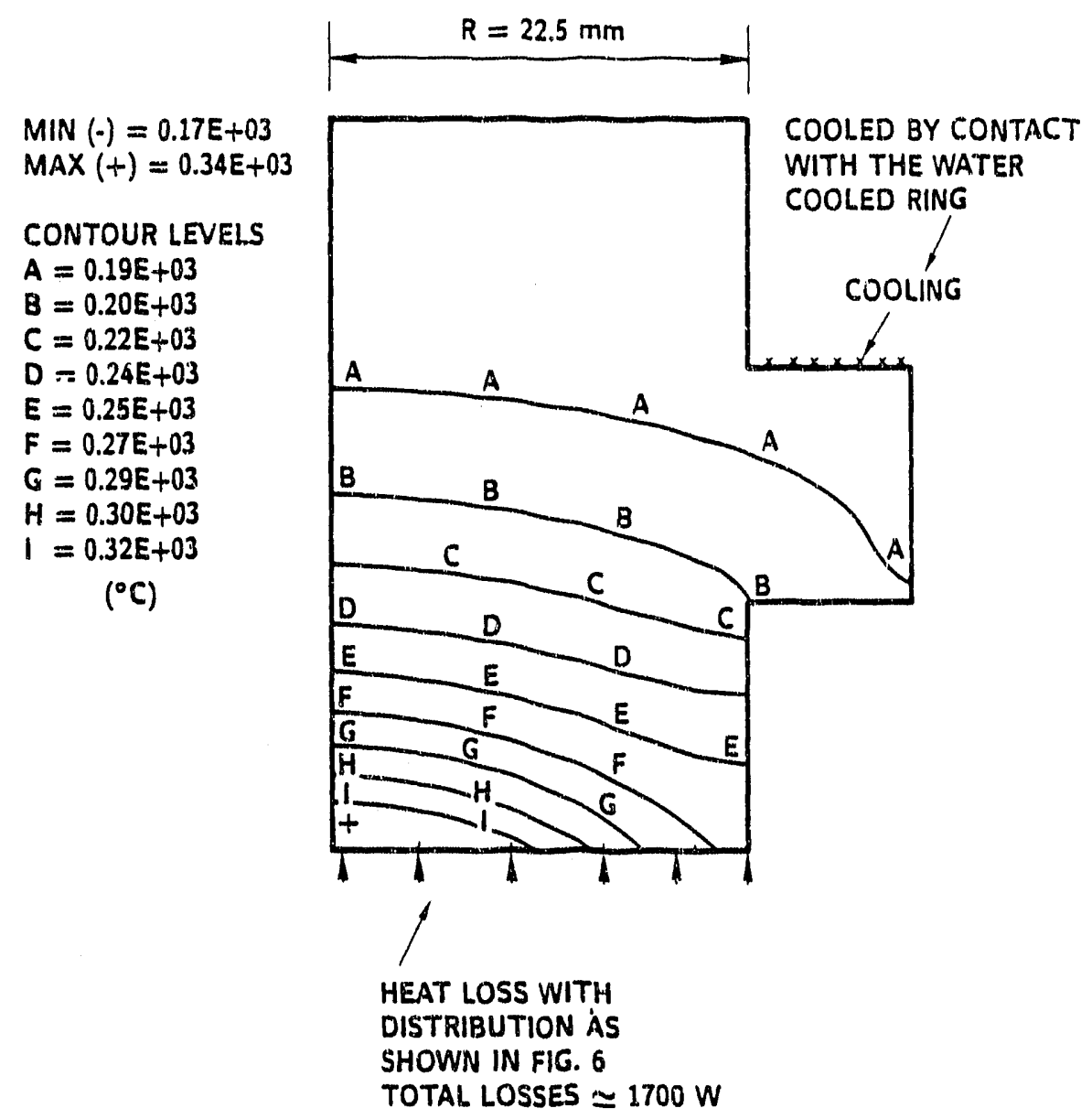

Fig. 8. Temperature distribution in the polarizer mirror at the end of $10 \mathrm{sec}$ pulse for $1 \mathrm{MW}$ of transmitted power. 

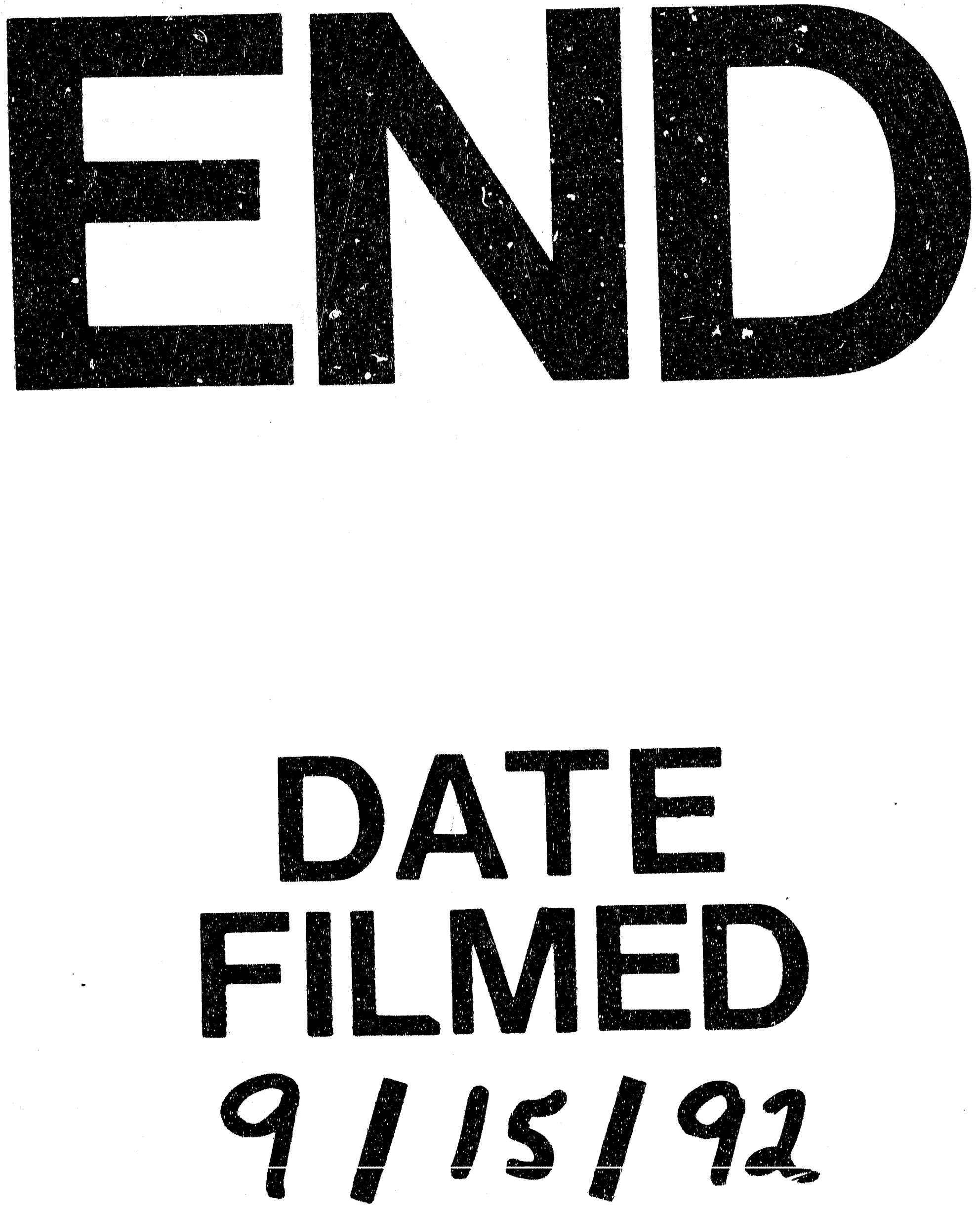
